International Journal of Engineering \& Technology, 7 (4.30) (2018) 145-148
International Journal of Engineering \& Technology
SPC
Website: www.sciencepubco.com/index.php/IJET
Research paper

\title{
Iot Based Weather Station Using Raspberry Pi 3
}

\author{
P Y Muck ${ }^{1}$ and M J Homam ${ }^{2}$. \\ ${ }^{1,2}$ Wireless and Radio Science Centre, Faculty of Electrical and Electronic Engineering, \\ Universiti Tun Hussein Onn Malaysia, 86400 Parit Raja, Batu Pahat, Johor, Malaysia \\ *Corresponding author E-mail: mariyam@uthm.edu.my
}

\begin{abstract}
Weather is the day-to-day state of atmosphere that is hard to predict which affects the activities of mankind and has great significance in many different domains. However, the current weather station in the market is expensive and bulky which cause inconvenience. The aim of this project is to design a weather station with real time notifications for climatology monitoring, interface it to a cloud platform and analyse weather parameters. In this project, a weather station is assembled using SparkFun Weather Shield and Weather Meter and Arduino Uno R3 to collect weather parameters. Data collected from the sensors are then stored into Google Cloud SQL using Raspberry Pi 3 Model B which acts as a gateway between them and analysis of weather data are done. A website and mobile application are developed using Google Data Studio and Android Studio respectively to display the real-time weather conditions in graphical presentation which are accessible by administrator and users. Users will receive notification regarding the weather conditions at that particular place on social media platform regularly and irregularly. Weather prediction is done in short term which allows users to get themselves prepared for their future plan in the next thirty minutes.
\end{abstract}

Keywords: Google Cloud Platform; Internet of Things; Raspberry Pi; SparkFun Weather Shield and Meter; Weather prediction.

\section{Introduction}

Weather condition plays an important role in our daily life as weather and climate are the most ubiquitous factors for home and environment planning. Moreover, the tremendous development of Internet nowadays made possible to monitor weather conditions and collect the respective data in-situ. All the objects, sensors and devices can be linked through Internet to share and analyze the data collected at various locations. The Internet of Things (IoT) can be much more extensive in predicting and knowing the weather conditions in particular place by connecting this weather station to the Internet.

The climate in general is capricious that is hard to predict nowadays [1]. With advanced technology to help humanity and bring convenience to the society, it is now the time for the weather broadcasting to be implemented into mobile phone instead of keep checking through only television or radio. However, with the mobile weather checking system we have in this era still often we see people rushing for schedule under the rain without umbrella; laundries are still showering by rain; home planted plants are wilted due to the hot and dry weather.

Therefore, the objective of this project is to create an online weather system which enables user to check real time weather parameters of a place anytime and anywhere with just a few buttons click. On top of that, people will receive real time notification or reminder. Weather prediction will be done which allows users to get themselves prepared for their plans in the current weather.

Google Cloud platform is chosen because it is easy to set up, easy to run, and with security built in features. It will be used to do data analysis and building a mobile weather checking applications. Google Cloud is suitable to be used in this project that needs sev- eral functions provided in this platform in order to obtain desired results. References [2] to [11] are some of the weather stations that have already been developed by other researchers.

\section{Design Methodology}

There are three phases to achieve the stated objectives. Figure 1 shows the architecture of the project.

A. Phase 1-Weather station design and prototype development

The weather parameters are measured using Sparkfun Weather Shield sensor and weather meter connecting to Arduino Uno R3 to capture all the data from the weather sensors. The measurements taken include temperature, humidity, atmospheric pressure, light intensity, wind speed and direction, and rain precipitation.

B. Phase 2-Transferring data to initial state cloud platform

Raspberry Pi 3 Model B is used as a gateway between sensors and IoT platform. It streamed and saved the data to Cloud platform directly via Wi-Fi. Cloud platform that is used in this project is Google Cloud SQL because it fully manages data, supports monitoring, logging, and diagnostics, data analysis and helps developers in building vertical applications.

C. Phase 3-Application of IoT and prediction phase

Stream of weather parameters/information can be displayed in a professional graphical fashion which can be accessed from Google Data Studio webpage. Google also allows the development of web applications that is reliable, fast and engaging. An application is created using Android Studio which allowed users to check the weather using mobile phone. Real time notification will then be sent to the user via social media regularly and irregularly. Weather prediction is done by using normal algorithm (i.e if-else operation) which allows users to get themselves prepared for their future plans. 


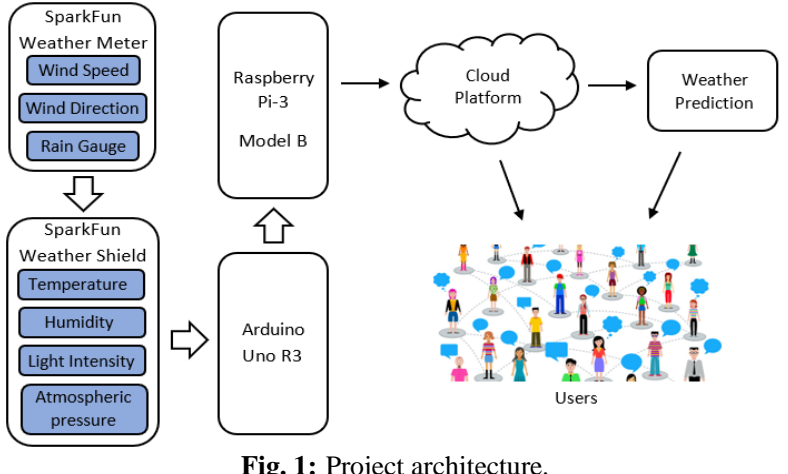

Fig. 1: Project architecture.

\section{Result}

This section presents and illustrates the results obtained from every phase from this project in both hardware and software.

\subsection{Hardware Design}

The hardware of weather station built using SparkFun Weather Shield and Meter which are connected to Arduino Uno R3 is shown in Figure 2. Raspberry Pi 3 Model B acted as a gateway between the sensors and the Cloud platform. It was located at open air to capture all the necessary weather parameters. Sensors and microcontrollers were protected by transparent casing to avoid malfunction due to the possibility of getting in touch with water.

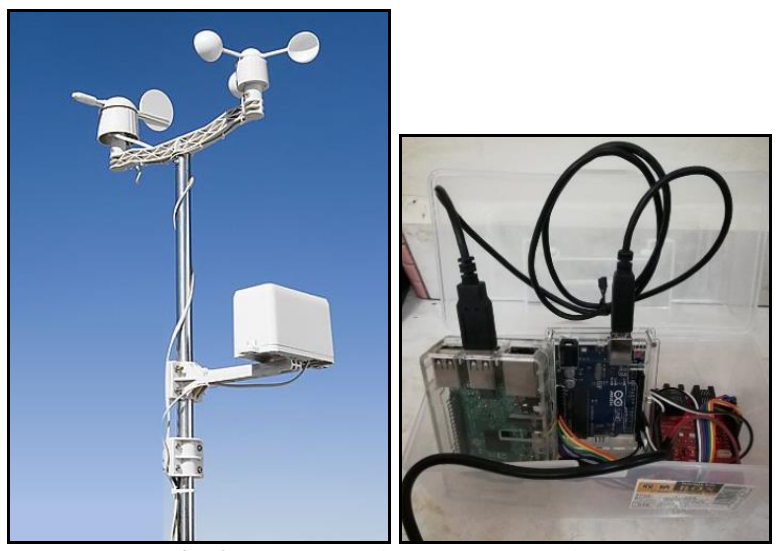

Fig. 2: Hardware of the weather Station.

\subsection{Storing weather data into Google Cloud SQL}

A table was created in Google Cloud SQL to allocate and save all the weather variables collected by the sensors. The system was programmed to save data into Google Cloud SQL every 2 minutes. Google Cloud SQL was chosen because it is easy to set up, easy to run and with security built in features. It can fully manage the weather parameters data of a whole year perhaps, and supports the integration of data from sensors on the Internet. Besides saving data into Google Cloud SQL, the data can be saved into the local SQL storage of the RPi3 Model B too which is known as phpMyAdmin. However, the data saved in local SQL storage was only accessible by administrator with username and password instead of users as shown in Figure 3.

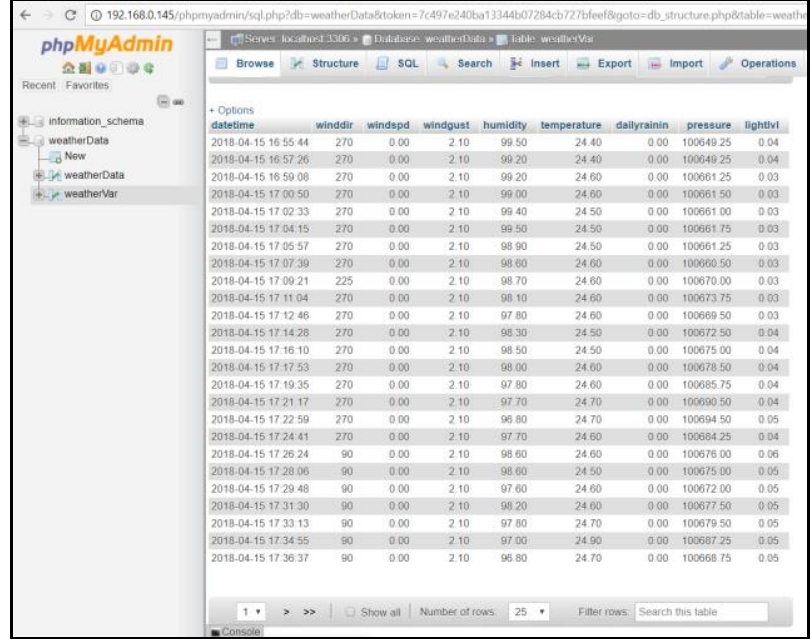

Fig. 3: Weather variables saved in a table in phpMyAdmin.

\subsection{Displaying weather data}

The data collected from the sensors were presented using various methods such as table, graph and chart in Google Data Studio as shown in Figure 4. It supports monitoring, logging, and diagnostics of weather conditions, and data analysis which can be accessed by both administrator and users through web page. The data shown in this web page encountered a delay of twelve seconds after the sensors took measurement. Therefore, the entire process from measurement to data presentation took around one minute and forty-two seconds due to time taken at measurement and delay at transferring data from sensors to Cloud. Users can filter dates of the data for viewing. Besides that, the data can also be exported by users in several formats such as CSV and Excel Sheets for personal usage. The data collected were further analyzed too.

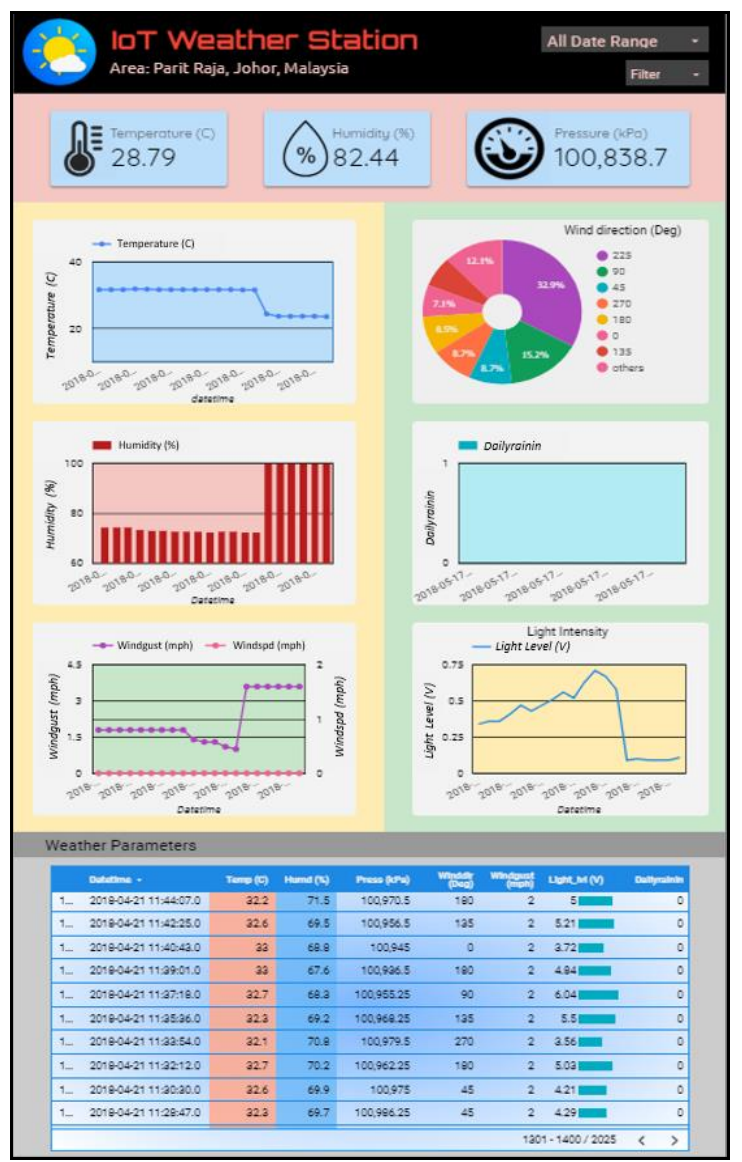

Fig. 4: Displaying of weather data using Google Data Studio report. 
From Figure 4, various parameters were displayed in the web report. However, the value of wind speed is zero because initially the weather station was located below the rooftop for testing that affected the accuracy reading of wind speed. It is supposed to be located at the rooftop to avoid blockage.

On top of that, a mobile application was created using Android Studio which enabled users to check weather using mobile anywhere and anytime as shown in Figure 5. App was written in Java programming language. An Android virtual device emulator was created to run app project on Windows and tested offline. In addition, the weather conditions were updated to social media regularly which was every two minutes and irregularly whenever the parameters exceed the threshold values to notify the users as shown in Figure 6. Table 1 tabulates the conditions in order for different notifications to be posted to social media.

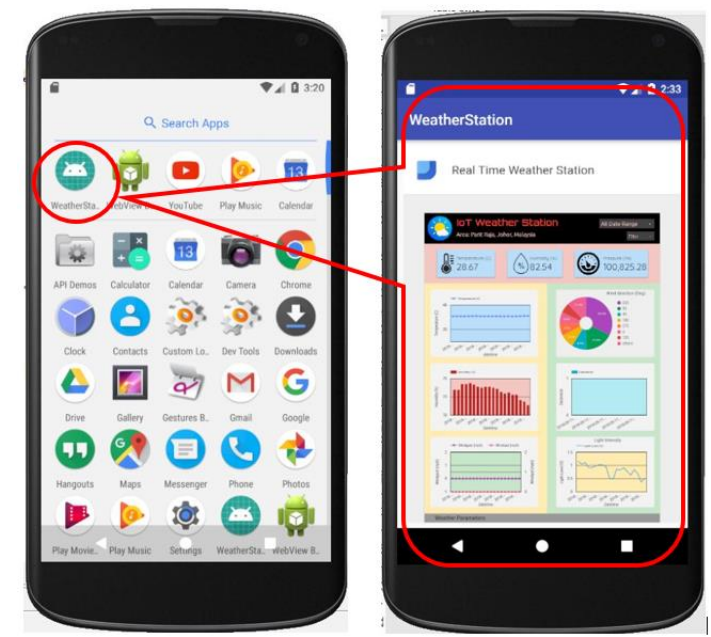

Fig. 5: The Android application of the weather station.

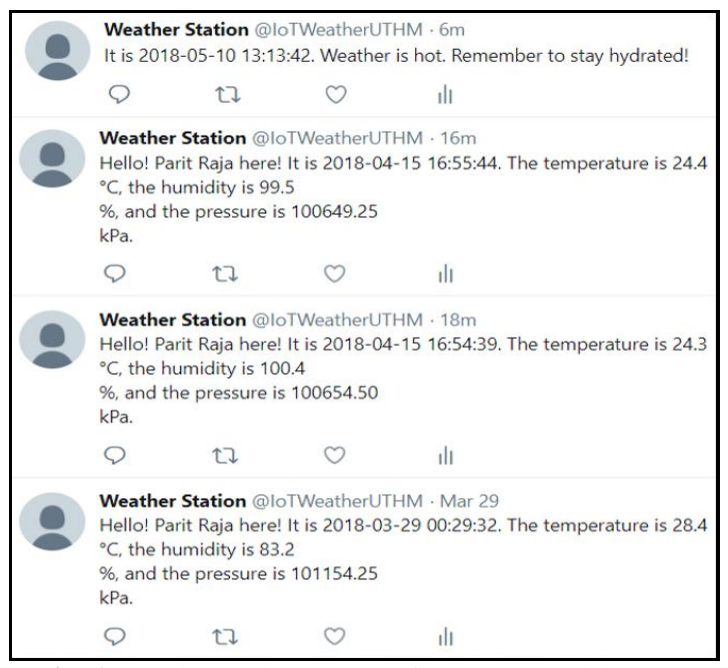

Fig. 6: Regular and irregular notifications on social media.

Table 1: The threshold value of every parameter for irregular notification to be triggered.

\begin{tabular}{|c|c|}
\hline Status & Conditions \\
\hline $\begin{array}{c}\text { Weather is hot. Remember to stay } \\
\text { hydrated! }\end{array}$ & Temperature $>33^{\circ} \mathrm{C}$ \\
\hline $\begin{array}{c}\text { It is cold outside. Keep yourself } \\
\text { warm! }\end{array}$ & Temperature $<21^{\circ} \mathrm{C}$ \\
\hline $\begin{array}{c}\text { It is raining outside. Remember to } \\
\text { bring umbrella! }\end{array}$ & Dailyrainin $>0.01 \mathrm{~mm}$ \\
\hline
\end{tabular}

\subsection{Weather prediction}

Initial short-term weather forecasting (i.e next thirty minutes to an hour) was done by using persistence forecasting method which relies on the current weather conditions due to the insufficient number of collected data. "If-else" algorithm was used to categorise the atmosphere states and send notifications to users via social media to remind users when the weather is predicted to be different from the current conditions as shown in Figure 7.

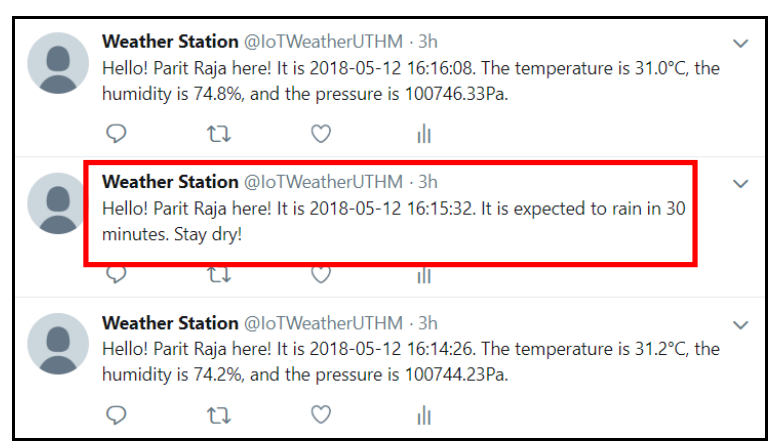

Fig 7: Predicted weather was sent to users via social media.

A decrease in pressure, light intensity based on photons, surrounding temperature, and increase in wind gust over the past few hours, serve to predict the approach of low pressure system and its associated increase in cloud cover which in turns bringing rain to that particular place. The values set were tabulated in Table 2 . The predicted weather variable values are subject to be changed based on the observations did every day. As in this case, the rain did not come in thirty minutes as expected but it came after three hours from the statement being made. Weather prediction cannot be done by machine learning method due to insufficient number of collected weather data.

Table 2: The parameters and values set for weather prediction

\begin{tabular}{|c|c|c|}
\hline Parameters & Threshold Values & Statement \\
\hline Temperature $\left({ }^{\circ} \mathrm{C}\right)$ & $<26$ & \multirow{2}{*}{ Expected to rain in } \\
Humidity $(\%)$ & $>80$ & 30 minutes \\
\hline Pressure $(\mathrm{kPa})$ & $<100,600$ & \\
\hline Light level $(\mathrm{V})$ & $<2.50$ & \\
\hline
\end{tabular}

\section{Conclusion}

In conclusion, a weather station was assembled using SparkFun Weather Shield and Weather Meter with Arduino Uno R3, and RPi3 Model B as the gateway between sensors and IoT Platform. The collected weather data were all being stored in a table in Google Cloud SQL neatly. All the weather parameters were successfully displayed via Google Data Studio using various graphical methods which are accessible by both administrator and users. An app was created by using Android Studio which allows users to check weather data with just a few buttons clicked. Initial weather prediction was done by using persistence method. However, the accuracy is low due to insufficient data

\section{References}

[1] Aguado E \& Burt J, Understanding Weather and Climate, 6th ed. Boston [Mass.]: Pearson Education, Inc., (2013).

[2] Kodali R \& Mandal S, "IoT based weather station", 2016 International Conference on Control, Instrumentation, Communication and Computational Technologies (ICCICCT), Kumaracoil, India, pp. 680-683, (2016).

[3] Ruano AE, Mestre G, Duarte H \& Silva S, "A neural network based intelligent weather station", 2015 IEEE 9th International Symposium on Intelligent Signal Processing (WISP), Siena, Italy, pp. 1-6, (2015).

[4] Yash M, Anshika M \& Bhateja D, "Correlation among environmental parameters using an online smart weather station system", India Conference (INDICON), 2015 Annual IEEE, New Delhi, India, pp. 1-6, (2015). 
[5] Gustavo CD, Alonso MG \& Felipe RM, "Monitoring system of a weather station via IP”, ANDESCON, 2010 IEEE, Bogota, Colombia, pp. 1-6, (2010).

[6] Satyanarayana KNV, Reddy SRN, Sai Teja PVYN \& Habibuddin B, "IOT Based Smart Weather Station Using Raspberry-PI3", Journal of Chemical and Pharmaceutical Sciences, Vol. 2016, No. 10, pp. 1-6, (2016).

[7] Savić T \& Radonjić M, "One approach to weather station design based on Raspberry Pi platform”, 2015 23rd Telecommunications Forum Telfor (TELFOR), Belgrade, Serbia, pp. 623-626, (2015).

[8] Krejcar O, "Low cost weather station with remote control", 2012 IEEE 10th International Symposium on Applied Machine Intelligence and Informatics (SAMI), Herl'any, Slovakia, pp. 463-468, (2012).

[9] Mircea P \& Catalin I, "Embedded weather station with remote wireless control", 2011 19th Telecommunications Forum (TELFOR) Proceedings of Papers, Belgrade, Serbia, pp. 297-300, (2011).

[10] Saini H, Thakur A, Ahuja S, Sabharwal N \& Kumar N, "Arduino based automatic wireless weather station with remote graphical application and alerts", 2016 3rd International Conference on Signal Processing and Integrated Networks (SPIN), Noida, India, pp. 605 $-609,(2016)$.

[11] Rafael L, Jorge A, Jose P \& Tomas S, "Ultra low power wireless weather station", 2007 International Conference on Sensor Technologies and Applications (SENSORCOMM 2007), Valencia, Spain, pp. 469-474, (2007). 